\title{
Bases teóricas e epistemológicas da abordagem dos perfis conceituais*
}

\author{
Eduardo F. Mortimer \\ Phil Scott2 \\ Charbel N. El-Hani
}

Artículo recibido: 04-04-2011 y aprobado: 15-07-2011

Theoretical and epistemological grounds of the conceptual profile approach

Resumo: Neste artigo, discutimos bases teóricas e epistemológicas da abordagem dos perfis conceituais, concebida como uma maneira de modelar a heterogeneidade do pensamento e da linguagem em salas de aula de ciências. Nós distinguimos entre duas visões sobre conceitos: (1) conceitos como modelos ou esquemas mentais de objetos ou eventos; (2) conceitos como exibindo significados relativamente estáveis e existindo apenas nas linguagens naturais e nos sistemas de conhecimento, e diferenciando-se da conceitualização, um processo dinâmico que ocorre nas mentes dos indivíduos, como resultado de interações socialmente situadas com eventos e experiências externas. Nós discutimos a aprendizagem da perspectiva da abordagem dos perfis conceituais, tratando-se como envolvendo os processos relacionados de enriquecimento de perfis conceituais e tomada de consciência tanto da heterogeneidade quanto da demarcação de modos de pensar e falar. Por fim, discutimos se a abordagem dos perfis conceituais é relativista, defendendo que ela é, antes, uma abordagem pragmatista objetiva.

Palavras chave: Perfis conceituais, Heterogeneidade do pensamento, Conceitos, Conceitualização, Pragmatismo objetivo.
Abstract: In this paper, we address the theoretical and epistemological grounds of the conceptual profile approach as a way of modeling the heterogeneity of thinking and speech in science classrooms. We distinguish between two views about concepts: (1) concepts as mental models or schemes of objects or events; (2) concepts as showing relatively stable meanings and existing only in natural languages or systems of knowledge, and differing from conceptualization, a dynamic process taking place in the individuals' minds, as a result of socially situated interactions with external events or experiences. We discuss learning as seen from the perspective of the conceptual profile approach, treating as encompassing the related processes of enriching conceptual profiles and promoting awareness of both the heterogeneity and demarcation of ways of thinking and speaking. Finally, we discuss whether the conceptual profile approach is relativistic, arguing that it is, rather, an objective pragmatist approach.

Key words: Conceptual profile, Heterogeneity of thinking, Concepts, Conceptualization, Objective pragmatism.

\footnotetext{
Atas do VII Encontro Nacional de Pesquisa em Educação em Ciências, 2009.

** Faculdade de Educação, Universidade Federal de Minas Gerais. e-mail: mortimer@ufmg.br

*** Centre for Studies in Science and Mathematics Education (CSSME). e-mail: p.h.scott@education.leeds.ac.uk

**** Departamento de Biologia Geral, Instituto de Biologia, Universidade Federal da Bahia. e-mails: charbel@ufba.br, charbel.elhani@pesquisador.cnpq.br
} 


\section{Introdução}

Salas de aula são lugares sociais complexos, nos quais um professor busca meios de interagir com dezenas de estudantes com o intuito de desenvolver um ponto de vista particular, no caso do ensino de ciências, a estória científica (Mortimer e Scott, 2003), com o objetivo de promover nos estudantes uma compreensão de conceitos científicos (El-Hani e Mortimer, 2007). Em qualquer sala de aula, há uma inevitável heterogeneidade de modos de pensar e falar, que precisam ser modelados se tivermos a intenção de produzir alguma teoria sobre o ensino e a aprendizagem.

Em meados dos anos 1990, Mortimer (1994, 1995) propôs os perfis conceituais como uma maneira de modelar a heterogeneidade do pensamento e da linguagem em salas de aula de ciências. Perfis conceituais devem ser entendidos, pois, como modelos de diferentes maneiras de ver e representar o mundo que são utilizadas pelas pessoas para significar sua experiência. Eles foram inicialmente desenvolvidos como uma alternativa ao modelo de mudança conceitual de Posner et al. (1982), recusando uma das idéias centrais deste modelo, a de que estudantes deviam ser levados a romper com suas concepções prévias ao aprender ciências. Esta é uma recusa que aproxima a abordagem dos perfis conceituais de outros desenvolvimentos, como o construtivismo conceitual de William Cobern (1996), que também propõem a coexistência de diferentes modos de pensar e falar como resultado da aprendizagem de ciências.

Em decorrência de desenvolvimentos posteriores, perfis conceituais foram integrados a um arcabouço teórico que trata a aprendizagem de ciências como a aprendizagem da linguagem social da ciência escolar, através de interações discursivas na sala de aula, entendidas de uma perspectiva sócio-interacionista (Mortimer \& Scott, 2003). Neste arcabouço, os seguintes referenciais são combinados numa síntese teórica que se mostra possível pelo compartilhamento de uma série de pressupostos, característicos de abordagens sóciointeracionistas ou sócio-culturais: a abordagem dos perfis conceituais, como ferramenta de análise de modos de pensar; a teoria da linguagem do círculo de Bakhtin, como referencial para análise de modos de falar; a teoria de desenvolvimento das funções mentais de Vigotski, como base para a análise da aprendizagem; a estrutura desenvolvida por Mortimer e Scott para a análise de abordagens comunicativas na sala de aula; e, mais recentemente, a análise da construção do conhecimento escolar em termos da sociologia da educação de Basil Bernstein. Não teremos espaço, no presente artigo, para tratar da integração destas várias perspectivas num único arcabouço teórico, sendo nosso intuito apenas situar a abordagem dos perfis conceituais dentro de um escopo mais amplo, passando agora a discuti-la de modo específico.

Para tanto, iniciaremos com uma discussão sobre a natureza dos conceitos, distinguindo duas visões a este respeito na literatura em ensino de ciências. Em seguida, trataremos dos perfis conceituais como maneira de modelar a heterogeneidade do pensamento e da linguagem em salas de aula. E finalizaremos com uma discussão das bases epistemológicas dos perfis conceituais, de modo a deixar claro que estas não abrigam um compromisso com o relati- 
Bases teóricas e epistemológicas da abordagem dos perfis conceituais

vismo, mas com outra posição filosófica, o pragmatismo objetivo (peirceano), que explicaremos brevemente, enfocando, sobretudo, sua diferenciação em relação ao relativismo e ao pragmatismo subjetivo (jamesiano).

\section{O que é um conceito?}

Na literatura sobre ensino de ciências, podemos encontrar duas abordagens distintas sobre conceitos e conceitualizações. Na visão dominante, conceitos são vistos como modelos ou esquemas mentais construídos pelos aprendizes que representam objetos ou eventos. Conceitos são tomados, assim, como entidades mentais relativamente estáveis que são possuídos por um indivíduo. Neste caso, a mudança ou evolução conceitual é entendida como um processo por meio do qual estes esquemas individuais sofrem algum tipo de transformação. Na educação científica, isso pode significar a aprendizagem pelo estudante de alguma forma do ponto de vista da ciência escolar.

Há na literatura, contudo, uma outra visão sobre conceitos, de acordo com a qual conceitos apenas existem no terceiro mundo popperiano (Popper, 1978; Wells, 2008), como parte da linguagem natural ou de sistemas de conhecimento, como a ciência. Conceitos não são encontrados, pois, no primeiro mundo popperiano, que corresponde ao universo físico, ou no segundo popperiano, pertinente à experiência consciente. Ainda segundo Popper, conceitos são parte do conhecimento no sentido objetivo, pertencente ao Mundo 3 e existindo apenas nos textos e na linguagem, como construtos sociais. No Mundo 2, da experiência consciente, encontramos conhecimento no sentido subjetivo, manifesto na forma de processos de pensamento, baseados, por sua vez, em processos cerebrais, pertencentes ao Mundo 1. A visão dos três mundos de Popper nos ajuda a compreender a diferença entre conceitos e conceitualizações, que desempenha papel muito mais importante nesta segunda visão do que na primeira visão sobre conceitos. Na mente de um indivíduo, como parte do segundo mundo popperiano, não encontramos instâncias de conceitos, mas um processo dinâmico, que podemos chamar de conceitualização, ou, seguindo a Vygotsky (1978), de pensamento conceitual.

A conceitualização é um processo emergente, sempre produzido na interação socialmente situada entre um indivíduo e alguma experiência externa. Quando estamos falando de indivíduos que dominam o significado de certo conceito, o pensamento conceitual é restringido por este significado, em decorrência dos processos educacionais pelos quais passaram aqueles indivíduos, mas, ainda assim, não se trata de que eles estejam 'lendo em voz alta' estruturas mentais mais ou menos estabilizadas, que corresponderiam aos conceitos. De uma perspectiva sóciointeracionista, o fato de que temos a impressão de que "possuímos" conceitos em nossa mente é um indício de quão poderosos são nossos processos de socialização. $\mathrm{O}$ aspecto de permanência no processo de conceitualização que nos leva a esta impressão pode ser entendido, de uma perspectiva vigotskiana, como uma tendência ou potencialidade de o pensamento conceitual, quando plenamente desenvolvido, operar de maneira similar diante de experiências que nós percebemos como similares. $\mathrm{O}$ 
pensamento conceitual, como processo emergente em cada interação com a experiência, tende a repetir-se em aspectos que nos parecem centrais, e é isso que nos permite usar conceitos repetidamente, de modo similar, e, assim, pensar através de conceitos e comunicarmo-nos uns com os outros de maneira efetiva por meio dos signos da linguagem. É evidente que estamos apoiando-nos, neste argumento, numa das idéias centrais de Vigotski, sua famosa lei genética geral do desenvolvimento cultural, segundo a qual "qualquer função no desenvolvimento cultural da criança aparece duas vezes, ou em dois planos. Primeiro, ela aparece no plano social, e então no plano psicológico. Primeiro, ela aparece entre as pessoas como uma categoria interpsicológica, e então dentro da criança como uma categoria intrapsicológica" (Vygotsky, 1978, p. 163).

Outra idéia de Vigotski ajuda a entender o que é permanente na conceitualização. Trata-se da distinção entre sentido e significado. Escreve Vigotski: "O sentido de uma palavra é o agregado de todos os fatos psicológicos que surgem em nossa consciência em conseqüência da palavra. O sentido é uma formação dinâmica, fluida e complexa que tem várias zonas que variam em sua estabilidade (...) Em diferentes contextos, o sentido de uma palavra muda" (Vygotsky, 1987, pp. 275-276). O significado, por sua vez, é um construto social relativamente mais estável, tornando possível a intersubjetividade, na medida em que duas ou mais pessoas podem compartilhar o significado de uma palavra, ainda que variem nos sentidos que atribuem a ela. A palavra se torna, desse modo, portadora do conceito (Vigotski, 2000, p. 154). Todos os contratos de comunicação
(Rommetveit, 1979) são estabelecidos com base nestes significados estáveis, construídos sócio-culturalmente e, como argumenta Vigotski, tendo a natureza de generalizações. Aprender um conceito é aprender seu significado, generalizar, passar de sentidos pessoais para significados socialmente aceitos. A produção de sentido, por sua vez, é um processo inteiramente pessoal: cada indivíduo produz sentidos diferentes para uma mesma palavra e o mesmo indivíduo pode também variar nos sentidos produzidos de contexto a contexto discursivo. Contudo, quando o pensamento conceitual está plenamente formado, a produção de sentido é restringida pelos significados socialmente aceitos. Não que os significados não possam mudar, mas, quando o fazem, trata-se de uma mudança que ocorre através de um processo social que, por assim dizer, se nutre da produção de sentidos dos sujeitos. Há uma interessante relação dialética entre sentido e significado. Se conseguimos aprender o significado das palavras ao longo de nosso desenvolvimento, isso se deu a partir da rica produção de sentidos que empreendemos quando crianças, sendo gradualmente restringidos pelos ambientes educacionais (formais e não formais) até que as palavras adquiriram para nós um significado generalizável, relativamente estável. Se os significados mudam ao longo da dinâmica social, esta transformação só é possível a partir da matéria prima da produção de sentidos pelos indivíduos. Em todo este processo, contudo, o significado de uma palavra nunca é algo puramente interno a uma pessoa; ele é, antes, um construto social que confere permanência ao nosso pensamento conceitual, não obstante sua complexa dinâmica. 
Bases teóricas e epistemológicas da abordagem dos perfis conceituais

Desta perspectiva, conceitos e conceitualizações são distinguidos: os primeiros existem de modo mais estável no terceiro mundo popperiano, no mundo do conhecimento objetivo construído socialmente e organizado na forma de linguagens sociais, incluindo as linguagens da ciência e da ciência escolar; as últimas são mais dinâmicas, embora restringidas pelos significados dos conceitos, sendo instanciadas no segundo mundo popperiano, o mundo da experiência consciente, do conhecimento subjetivo. Conceitos e conceitualizações estabelecem entre si uma relação dialética, tal como capturada na relação entre significado (próprio dos conceitos) e sentido (produzido pelo pensamento conceitual ou conceitualização). De acordo este modo de entender os conceitos, é graças à restrição da produção de sentidos pelos significados socialmente estabilizados que nos tornamos capazes de pensar conceitualmente de modo tão repetível que terminamos por conceber os conceitos como entidades mentais estáveis.

Certamente, temos aqui uma oposição entre duas visões diametralmente opostas, talvez até mesmo incomensuráveis, e um pesquisador terá de optar por entender os conceitos de um modo ou de outro. Nossa opção é pela visão sócio-interacionista descrita acima, porque nos parece que o tratamento dos conceitos como esquemas ou modelos mentais estáveis obscurece uma distinção crucial trazida à tona por Popper, a saber, entre o mundo da experiência consciente e o mundo das linguagens construídas socialmente.

Uma visão sócio-interacionista sobre os conceitos implica também a possibilidade de diferentes maneiras de conceitualizar nossa experiência, com base na variedade de contextos em que ela tem lugar. Esta é uma idéia básica da abordagem dos perfis conceituais.

\section{A abordagem dos perfis conceituais}

Muitos autores argumentam que as pessoas têm diferentes maneiras de ver e conceitualizar o mundo (e.g., Schutz, 1967; Tulviste, 1991; Cobern, 1996). Pode-se argumentar, contudo, que as pessoas lidam com "representações coletivas" (Durkheim, 1972) ao construírem seu pensamento conceitual. Estas construções coletivas - como preferimos chamá-las - têm natureza supra-individual (ou seja, social) e são impostas à cognição individual. Desse modo, terminamos por lidar com conceitos e significados que são mantidos numa forma bastante similar por uma série de indivíduos, em variadas esferas do mundo social, tornando possível a comunicação efetiva. Quando Vigotski destacou a dimensão social dos processos mentais humanos, como fez em sua lei genética geral do desenvolvimento cultural, ele estava apoiando-se neste modo de compreender a construção do pensamento conceitual (Kozulin, 1990). A imposição de tais construções coletivas à cognição individual decorre do fato de que esta se desenvolve mediante a internalização de ferramentas culturais que são tornadas disponíveis através de interações sociais. Como nossa experiência social é diversa e multifacetada, segue que não compartilhamos apenas uma série de conceitos a partir dos quais significamos nossa experiência; ao contrário, temos à disposição uma diversidade de significados estabilizados em diferentes linguagens sociais, sendo que o peso que damos a cada um deles depende da extensão em 
que tivemos oportunidades, ao longo de nossa formação, para empregá-los de modo fértil para dar conta dos desafios colocados por nossas experiências.

A abordagem dos perfis conceituais é baseada, precisamente, na idéia de que as pessoas exibem diferentes maneiras de ver e conceitualizar o mundo e, desse modo, diferentes modos de pensar que são usados em contextos distintos (Mortimer, 1994, 1995, 2000). Perfis conceituais devem ser entendidos como modelos da heterogeneidade do pensamento verbal (Tulviste, 1991). Modos de pensar são tratados como elementos de permanência no pensamento conceitual dos indivíduos, intimamente relacionados a significados socialmente construídos que podem ser atribuídos aos conceitos.

Cada perfil conceitual modela a diversidade de modos de pensar ou de significação de um dado conceito (e.g., calor, matéria, vida, adaptação) e é constituído por várias "zonas". Cada zona representa um modo particular de pensar ou atribuir significado a um conceito. Cada modo de pensar pode ser relacionado a um modo particular de falar, como discutiremos mais adiante.

Torna-se mais fácil compreender a natureza deste modelo da diversidade de modos de pensar quando consideramos alguns aspectos de sua metodologia de construção. Como não poderemos detalhar esta metodologia, indicamos aos leitores interessados a leitura de outros trabalhos nas quais ela é discutida (Amaral \& Mortimer, 2006; Sepulveda, Mortimer e El-Hani, 2007). Consideramos fundamental estar atento ao caráter da metodologia usada na construção de perfis, para que as investigações realizadas sejam de fato consideradas parte do programa de pesquisa a respeito de tais modelos. Primeiro, é importante destacar que, para construir um perfil conceitual, é estritamente necessário considerar uma grande diversidade de significados atribuídos a um conceito e uma variedade de contextos de produção de significados, incluindo pelo menos três dos quatro domínios genéticos considerados por Vigotski em seus estudos sobre as relações entre pensamento, linguagem e formação de conceitos, a saber, os domínios sócio-cultural, ontogenético e microgenético (Wertsch, 1985). O que se busca nos dados relativos à produção de significado nestes domínios genéticos são compromissos ontológicos e epistemolégicos que estabilizam modos de pensar e falar sobre os conceitos e, assim, tornam possível individuar zonas para a construção de um perfil. Para buscar estes compromissos, devem ser considerados dados de uma variedade de fontes, de uma maneira dialógica, e não seqüencial, de maneira a colocar todos os conjuntos de dados ao mesmo tempo em interação uns com os outros. Entre as fontes que podem ser usadas, estão: (1) fontes secundárias sobre a história da ciência e análises epistemológicas sobre o conceito em estudo, que são particularmente instrumentais na compreensão da produção de significados no domínio sócio-cultural e no estabelecimento de compromissos ontológicos e epistemológicos que norteiam os processos de significação de um conceito; (2) trabalhos sobre concepções alternativas de estudantes, que são úteis para compreender a significação dos conceitos no domínio ontogenético; e (3) dados colhidos através de entrevistas, questionários e filmagens de interações 
Bases teóricas e epistemológicas da abordagem dos perfis conceituais

discursivas numa variedade de contextos de produção de significado, particularmente em situações educacionais, que dão acesso aos domínios ontogenético e microgenético ${ }^{1}$.

É importante enfatizar que a construção de zonas de um perfil conceitual vai além da categorização do discurso escrito ou oral, embora tipicamente envolva este procedimento. A necessidade de ir além da categorização se torna clara, contudo, quando se considera que as zonas de um perfil são individuadas por meio de compromissos ontológicos e epistemológicos que estruturam diferentes modos de pensar e falar sobre um conceito, e estes não são dados explicitamente em declarações ou proposições. É preciso, por assim dizer, cavar de modo mais profundo nas afirmações dos sujeitos de modo a interpretá-las em termos de um repertório de compromissos ontológicos e epistemológicos elaborados como hipóteses e constantemente reformulados pelo investigador, à luz de suas fontes de dados. Por fim, vale a pena considerar que a obtenção e interpretação dos dados obtidos nas fontes citadas são entendidas em termos de um processo de dialogo estruturado pelas intenções e procedimentos do investigador (Martins, 2006). Assim, em momento algum as evidências são entendidas como "dados brutos", a partir dos quais se poderiam obter categorias e, subsequentemente, compromissos ontológicos e epistemológicos de modo indutivo. É a interpretação ativa do investigador, munido das hipóteses que o diálogo entre suas fontes de dados lhe permite formular, que permite trabalhar tais compromissos e, assim, individuar zonas de um perfil.

Cada indivíduo tem um perfil conceitual próprio, que se diferencia dos perfis de outros sujeitos pelo peso dado a cada zona, e não pelas zonas propriamente ditas. Como discutido acima, estas são modos de pensar e significar supraindividuais, sociais, que são impostos à cognição individual ao longo de seu processo de formação. As diferenças entre perfis resultam da diversidade da experiência social dos indivíduos, na medida em que esta pode oferecer mais ou menos oportunidades para empregar distintos modos de pensar nos contextos em que são pragmaticamente poderosos.

A heterogeneidade dos modos de pensar não se dá apenas no contexto da linguagem cotidiana. As ciências também abrigam formas heterogêneas de pensar e falar, propiciando múltiplas maneiras de conceitualizar a experiência. O conceito de átomo oferece um exemplo. Químicos podem usar o modelo de Dalton, no qual o átomo é visto como uma esfera rígida e indivisível, para explicar várias propriedades das substâncias. Fórmulas estruturais, por exemplo, utilizam tal representação dos átomos. Contudo, este modelo não é adequado para explicar outros fenômenos, como, por exemplo, a reatividade química, que demandam modelos diferentes do átomo, como aqueles derivados da mecânica quântica.

\footnotetext{
1 É importante ter clareza de que não estamos propondo relações biunívocas entre domínios genéticos e fontes de dados, mas apenas ilustrando algumas relações que foram instrumentais em investigações anteriores sobre perfis conceituais.
} 
Diante desta heterogeneidade, o que significa dizer que um estudante aprende sobre átomos na escola? Perfis conceituais, como modelos da heterogeneidade do pensamento, consideram que os diferentes significados que podem ser atribuídos a um conceito coexistem num indivíduo, mas cada qual se mostra pragmaticamente mais poderoso para lidar com determinados tipos de problemas, como fica claro no exemplo de conceito de átomo discutido acima. Não há qualquer garantia, no entanto, de que um indivíduo de fato opte pelos significados apropriados para uso em determinados contextos. Isso é algo a ser aprendido e aprender a este respeito significa aprender sobre a própria heterogeneidade do pensamento e da linguagem na diversidade de contextos em que usamos nossas idéias e declarações. Considere-se, além disso, que a heterogeneidade do pensamento conceitual não se limita necessariamente à ciência. Inúmeros "termos científicos" são também usados nas experiências cotidianas, seja porque são palavras da linguagem comum das quais a ciência se apropriou, como "adaptação", seja porque são palavras da ciência que foram apropriadas pela linguagem comum, como "gene". Nestes casos, os perfis conceituais são ainda mais ricos e a distinção entre significados diferentes e os domínios apropriados de sua aplicação se torna ainda mais complicada.

Neste cenário, é preciso examinar como a aprendizagem é entendida na abordagem dos perfis conceituais em termos de dois processos interligados: (1) o enriquecimento dos perfis conceituais; (2) a tomada de consciência da multiplicidade de modos de pensar que constituem um perfil e dos contextos nos quais estes modos de pensar e os significados que eles engendram podem ser aplicados de modo apropriado, i.e., pragmaticamente poderoso (El-Hani e Mortimer, 2007). No ensino de ciências, o primeiro processo tipicamente envolve a compreensão de modos científicos de pensar aos quais os estudantes geralmente não têm acesso por outros meios. O segundo processo segue de uma necessidade colocada por uma idéia central da abordagem dos perfis, a saber, de uma coexistência de modos de pensar e significados na cognição humana. Diante de tal coexistência, torna-se um objetivo crucial do ensino e da aprendizagem a promoção de uma visão clara, entre os estudantes, da demarcação entre modos de pensar e significados, bem como entre seus contextos de aplicação.

Considere-se, por exemplo, o caso de um estudante que aprende o conceito científico de que o calor é um processo de transferência de energia entre sistemas a diferentes temperaturas. Isso corresponde ao primeiro processo mencionado acima, o enriquecimento de seu perfil conceitual de calor (cf. Amaral \& Mortimer 2001). Em sua vida cotidiana, contudo, ele atuará em vários contextos discursivos que reforçam outra zona do perfil, como, por exemplo, a visão comum de que o calor é uma substância e de que é proporcional à temperatura, podendo haver um "calor quente" e um "calor frio". Por exemplo, o estudante muito provavelmente pedirá um "casaco quente de lã” em uma loja, na medida em que este modo de falar é muito mais apropriado para se comunicar neste contexto do que solicitar "um casaco feito de um bom isolante térmico, que 
Bases teóricas e epistemológicas da abordagem dos perfis conceituais

evite a transferência de energia térmica do corpo para o ambiente". No entanto, o uso da linguagem sempre tem conseqüências, em virtude de sua íntima relação com o pensamento (Whorf, 1940; Vigotski, 1978, 1987, 2000). Assim, a cada vez que o estudante usa esse modo cotidiano de falar sobre o calor, o valor pragmático da linguagem cotidiana preserva significados que estão em desacordo com a visão científica. Parece impossível, assim, que estes significados sejam substituídos por aqueles cientificamente aceitos.

O que fazer, então, para promover no estudante uma compreensão e, logo, uma aprendizagem (El-Hani e Mortimer, 2007) bem sucedida da visão científica sobre o calor? O segundo objetivo mencionado acima fornece uma resposta, de acordo com a abordagem dos perfis conceituais: é necessário promover nos estudantes uma tomada de consciência de que há uma diversidade de modos de pensar sobre o calor, mas eles não se mostram igualmente poderosos para resolver problemas que encontramos em nossas vidas e necessitam da mobilização de tal conceito. Um destes contextos é, decerto, o contexto escolar. Imaginem que, assim que o estudante pede um casaco quente na loja, seu professor, que passava por ali, lhe pergunte se, de fato, o casaco possui a propriedade de ser quente, e o estudante responda que o "calor" da lã é, na verdade, a propriedade de a lã ser um isolante térmico, que dificulta a transferência de energia de nosso corpo para o ambiente. O estudante terá mostrado uma consciência da heterogeneidade do pensamento sobre o calor e da demarcação entre os domínios de aplicação de diferentes significados atribuídos a este conceito, sendo capaz, assim, de usar idéias científicas e cotidianas sobre o calor de maneira complementar.

Embora possa parecer que a pergunta do professor tenha mostrado um uso da compreensão científica do calor na vida cotidiana, o que teria ocorrido nesta situação, em nosso entendimento, seria um deslocamento do estudante, ao ouvir a pergunta do professor, para um contexto escolar. É importante, assim, usar exemplos - tanto neste argumento, quanto em sala de aula - que mostrem o valor pragmático do modo de pensar científico no cotidiano. Embora seja conveniente falar sobre coisas quentes e frias numa variedade de situações, em outras circunstancias da vida cotidiana a visão científica do calor como um processo de transferência de energia é muito mais poderosa do que a visão de senso comum do calor e do frio como substâncias ou propriedades dos materiais. Considere-se, por exemplo, uma situação na qual uma pessoa deve escolher entre um copo de vidro e um copo de alumínio para beber uma bebida gelada num dia quente. A visão de senso comum a levará a escolher o copo de alumínio, porque ele é "frio", mas isso significará que sua bebida esquentará mais rápido, uma vez que a sensação térmica que temos ao tocar o copo de alumínio decorre de ele ser um melhor condutor térmico do que o vidro. Nesta situação encontrada no cotidiano de todos nós, a visão científica se mostra pragmaticamente mais poderosa. Tomar consciência de um perfil conceitual e da demarcação entre suas zonas implica ser capaz de aplicar uma idéia científica nos contextos em que ela é apropriada, inclusive na vida cotidiana, e, ao mesmo tempo, preservar modos de pensar e fa- 
lar distintos do científico nas situações em que se mostrem pragmaticamente apropriados. Trata-se de uma coexistência entre diferentes modos de pensar e falar, bem como de uma maneira de entender o ensino e a aprendizagem das ciências que os tornam não somente mais sensíveis à diversidade cultural, mas também mais factíveis, na medida em que não tomamos como objetivo deslocar ou substituir visões que são reforçadas a cada momento por nossa linguagem cotidiana. Em termos das estratégias de sala de aula, o objetivo da tomada de consciência indica a importância da aplicação das idéias científicas a uma variedade de circunstâncias como um aspecto importante do ensino de ciências.

Por fim, devemos considerar como perfis conceituais se inserem na análise de interações discursivas em sala de aula, que também tem constituído um importante foco de pesquisa de muitos grupos que os empregam. De acordo com van Dijk (1997), uma caracterização do discurso como um fenômeno social demanda que ele seja concebido como um evento comunicativo socialmente situado, no qual pessoas interagem para comunicar idéias, crenças ou emoções. Nesses termos, a descrição integrada de três dimensões do discurso é usualmente tomada como objeto de investigação: (1) o uso da linguagem - um fenômeno lingüístico; (2) a comunicação de idéias e crenças - um fenômeno cognitivo; e (3) a interação em contextos sociais - um fenômeno social.

Perfis conceituais constituem uma ferramenta poderosa para analisar a dimensão cognitiva do discurso. $\mathrm{O}$ exame desta dimensão corresponde a uma análise dos significados socialmente esta- belecidos que são atribuídos a um dado conceito a partir de distintos modos de pensar. Estes modos de pensar e os significados associados a eles são compartilhados por diferentes indivíduos, sendo necessária uma ferramenta para analisar esses modos estáveis de produção de significado que emergem nas interações discursivas em sala de aula. Os perfis conceituais são, assim, um pólo de uma análise do discurso estruturada em torno da relação entre modos de pensar e formas de falar (Mortimer, 2001): enquanto perfis conceituais são ferramentas poderosas para analisar modos de pensar, formas de falar podem ser analisadas com proveito em termos das linguagens sociais e gêneros do discurso de Bakhtin (1986). Este não é o espaço, contudo, para discutir em maiores detalhes a relação entre modos de pensar e formas de falar.

\section{As bases epistemológicas dos perfis conceituais}

A abordagem dos perfis conceituais pode ser acusada de ser relativista, por considerar que, ainda que novas formas de atividade dêem origem a novos tipos de pensamento, tipos mais antigos de pensamento são preservados e continuam a funcionar bem em seus contextos apropriados (Wertsch, 1991). Não se trata, contudo, de uma visão relativista, como argumentaremos brevemente nesta seção, mas uma visão pragmatista objetiva, tal como proposta por Charles Peirce.

Os debates sobre o relativismo e sua contraparte, o racionalismo, dizem respeito principalmente à apreciação e escolha de teorias, mas são também relacionados ao problema da demarcação entre ciência e outras formas de conhe- 
Bases teóricas e epistemológicas da abordagem dos perfis conceituais

cimento. Colocando o debate em termos extremos, um racionalista afirma que pode haver um critério único, atemporal e universal para avaliar os méritos relativos de teorias rivais, como, por exemplo, o critério popperiano de falseabilidade (Popper, 1975). Um relativista, por sua vez, nega a existência de um critério racionalista universal e ahistórico que possa orientar nossos juízos e decisões acerca de teorias. O que é melhor ou pior no que respeita às teorias científicas varia de indivíduo para indivíduo e/ ou de comunidade para comunidade. $\mathrm{O}$ objetivo da construção do conhecimento dependerá do que é considerado importante por um indivíduo ou comunidade (Chalmers, 1993).

É correto ver no pragmatismo certa proximidade ao relativismo, na medida em que, não obstante as muitas variedades de filosofias pragmatistas, um tema básico compartilhado por toda a tradição do pragmatismo é uma forte ênfase sobre a inserção (embeddedness) de toda e qualquer construção cognitiva humana nas práticas e nos discursos (ElHani e Pihlström, 2002; Pihlström, 1996). Mas há também um distanciamento entre pragmatismo e relativismo que não pode ser negligenciado. Se enfocarmos, em particular, a preocupação epistêmica com o significado e a verdade, o pragmatismo filosófico pode ser caracterizado, em termos gerais, pela idéia de que a eficácia na aplicação prática oferece um critério ou padrão para a determinação da verdade dos enunciados (Rescher, 1995). Assim, não se trata de que pragmatistas simplesmente rejeitem a noção da verdade como algum tipo de relação entre conhecimento e realidade; sua intenção é, antes, esclarecer o significado de tal relação mediante um apelo às ações, embora haja substancial variação entre os pragmatistas quanto ao modo de realizar tal esclarecimento.

Pragmatistas buscam explorar as conseqüências de nosso conhecimento sobre o mundo ser necessariamente moldado, ao menos em parte, pelos conceitos que nós mobilizamos para a tarefa de descrever e explicar o mundo. Uma das principais conseqüências deste reconhecimento do papel dos conceitos em nossas atividades cognitivas reside na impossibilidade de se aceitar alguma relação simples entre conhecimento e realidade, de acordo com a qual a mente poderia ser uma espécie de espelho do mundo. O conhecimento é simultaneamente iluminador e limitante, uma vez que não pode capturar de maneira perfeita todos os aspectos do mundo. De um lado, não é incomum encontrarmos entre os filósofos este reconhecimento da natureza dual do conhecimento como criando possibilidades e, ao mesmo tempo, impondo limites à nossa compreensão. Um traço distintivo do pensamento pragmatista, contudo, é o de que este reconhecimento é tomado como base para a proposição de que o conhecimento deve ser julgado, ao menos em parte, em termos de sua utilidade. Entretanto, a correta interpretação desta afirmação requer um esclarecimento do significado que se está atribuindo ao termo "utilidade". Não se trata de restringir os juízos sobre o conhecimento às aplicações práticas, na medida em que se reconhece a extrema utilidade do conhecimento para muitas outras coisas além de tais aplicações, por exemplo, como um instrumento de pensamento (Lotman, 1988, citado por Wertsch, 1991), i.e., como um instrumento para produzir novos significados. 
Desta idéia de que a utilidade é um critério central para os juízos sobre o conhecimento, segue que não se pode afirmar que vale tudo em nossos esforços de usar o conhecimento para decidir como agir em circunstâncias específicas. Afinal, há um número limitado de idéias e modos de pensar que podem ser bem sucedidos para lidar com qualquer problema dado. Ao distinguir entre os domínios de aplicação de distintos modos de pensar e dos significados associados a eles, a abordagem dos perfis conceituais se apóia nesta idéia de um valor pragmático de distintas formas de conhecimento para lidar com diferentes problemas. É neste sentido que esta abordagem não está comprometida com o relativismo, ou, ao menos, com relativismos do tipo "vale tudo" (cf. Feyerabend 1993).

Outra distinção importante deve ser traçada no interior do pragmatismo, entre pragmatismo objetivo, que preserva um papel para a objetividade em seu tratamento da relação entre conhecimento e realidade, e pragmatismo subjetivo, que é formulado apenas em termos do que se mostra efetivo para a realização dos propósitos de uma dada pessoa ou grupo (Rescher, 1995). Se, de um lado, não podemos mais manter uma distinção entre o que é objetivo e o que é subjetivo em termos do que está de acordo com o mundo e do que é a visão de um sujeito, de outro, parecemos necessitar, ainda, de alguma maneira de distinguir entre a confiança que podemos depositar no que constitui conhecimento compartilhado e no que se limita a uma opinião pessoal. Shrader-Frechette e McCoy (1994) sugerem uma maneira de ressignificar o conceito de objetividade que torna possível manter tal distinção.
Em sua visão, a objetividade não é um atributo as proposições, como geralmente se pensa, mas das práticas humanas de construção de conhecimento. Uma prática epistêmica é objetiva, desta perspectiva, se for caracterizada pela busca de imparcialidade nas ações e decisões, ainda que a completa imparcialidade seja obviamente impossível para agentes incorporados e situados. Entretanto, é pela busca de alcançar esta meta impossível que nos tornamos capazes de regular nossas práticas, exercitando a crítica mútua e tornando-nos mais informados sobre os vieses que afetam a construção do conhecimento, além de adotarmos procedimentos que tornam possíveis evitar vieses ou inclinações subjetivas, ao menos em alguma medida. A abordagem dos perfis conceituais se afasta do subjetivismo ao enfatizar o papel da apreciação racional das escolhas de modos de pensar e agir, como se torna manifesto na proposta da tomada de consciência sobre a demarcação de modos de pensar e seus domínios de aplicação como um objetivo de aprendizagem. Torna-se possível, assim, a construção de uma dimensão crítica, a qual pode permitir que se vá além de juízos subjetivos sobre o que é útil para os propósitos de uma única pessoa ou grupo.

Devemos admitir que ainda se pode argumentar que o pragmatismo não é, no fundo, muito diferente do relativismo. Contudo, pensamos que a distinção central que queremos traçar se afirma de modo seguro: trata-se de distinguir entre relativismos do tipo "vale tudo" - como encontramos em algumas perspectivas multiculturais (ver discussão em El-Hani e Mortimer, 2007) - e as bases pragmatis- 
Bases teóricas e epistemológicas da abordagem dos perfis conceituais

tas da abordagem dos perfis conceituais. Se alguém preferir chamar esta última posição de "relativismo", não temos problema em relação a isso, desde que não se confunda este "relativismo" com aquele outro, o relativismo "vale tudo".

\section{Conclusões}

Neste artigo, apresentamos de maneira sistemática a abordagem dos perfis conceituais, destacando sua íntima relação com uma visão sócio-interacionista sobre a natureza dos conceitos, como elementos do mundo das linguagens e dos sistemas de conhecimento, e do pensamento conceitual, como processo instanciado na mente dos indivíduos. Perfis conceituais foram caracterizados de modo detalhado, assim como sua metodologia de construção, enfatizando-se seu caráter de modelos da diversidade de modos de pensar e dos significados associados a um dado conceito. Discutimos, ainda, como perfis conceituais se inserem na análise de interações discursivas em sala de aula, constituindo uma ferramenta poderosa para analisar a dimensão cognitiva do discurso. Também foram discutidos requisitos metodológicos que devem ser observados para que um estudo seja considerado parte do programa de pesquisa sobre perfis conceituais, com base na estrutura teórica desta abordagem. Por fim, tratamos das bases epistemológicas da abordagem dos perfis, diferenciando o compromisso com o pragmatismo objetivo subjacente a ela de uma adesão ao relativismo, ao menos na forma de um relativismo "vale tudo".

\section{Bibliografía}

Amaral, E. M. R., e Mortimer, E. F. (2001). Uma proposta de perfil conceitual para o conceito de calor. Revista Brasileira de Pesquisa em Educação em Ciências, 1, 5-18.

Amaral, E. M. R., e Mortimer, E. F. (2006). Uma metodologia para estudar a dinâmica entre as zonas de um perfil conceitual no discurso da sala de aula. In: F.M.T. dos Santos \& I. M. Greca (Eds.) A pesquisa em ensino de ciências no Brasil e suas metodologias. Ijuí: Editora UNIJUÍ.

Bakhtin, M. M. (1986). Speech genres and other late essays. Austin, TX: University of Texas Press.

Chalmers, A.F. (1993). O que é ciência, afinal? São Paulo: Brasiliense.

Cobern, W. W. (1996). Worldview theory and conceptual change in science education. Science Education, 80, 579-610.

Durkheim, E. (1972). Selected writings. Cambridge: Cambridge University Press.

El-Hani, C. N., e Mortimer, E. F. (2007). Multicultural education, pragmatism, and the goals of science teaching. Cultural Studies of Science Education, 2, 657-702.

El-Hani, C. N., e Pihlström, S. (2002). A pragmatic realist view of emergence. Manuscrito, XXV, 105-154.

Feyerabend, P. K. (1993). Against method (3rd ed.). London: Verso.

Geelan, D. R. (1997). Epistemological anarchy and the many forms of constructivism. Science \& Education. 6(1-2): 15-28.

Kozulin, A. (1990). Vygotsky's psychology: A biography of ideas. New York, NY: Harvester Wheatsheaf. 
Martins, I. (2006). Dados como diálogo - Construindo dados a partir de registros de observação de interações discursivas em salas de aula de ciências. In: F.M.T. dos Santos \& I.M.R. Greca (Eds.), A pesquisa em ensino de ciências no Brasil e suas metodologias (pp. 297-321). Ijuí, RS: Editora Unijuí.

Mortimer, E. F. (1994). Evolução do atomismo em sala de aula: Mudança de perfis conceituais. Tese (Doutorado em Educação) - Faculdade de Educação, Universidade de São Paulo, São Paulo.

Mortimer, E. F. (1995). Conceptual change or conceptual profile change? Science \& Education, 4, 265-287.

Mortimer, E. F. (2000). Linguagem e formação de conceitos no ensino de ciências. Belo Horizonte, MG: Editora UFMG.

Mortimer, E. F. (2001). Perfil conceptual: Formas de pensar y hablar em las classes de ciencias. Infancia y Aprendizaje, 24, 475-490.

Mortimer, E. F., \& Scott, P. H. (2003). Meaning making in secondary science classrooms. Maidenhead, UK: Open University Press.

Pihlström, S. (1996). Structuring the world: The issue of realism and the nature of ontological problems in classical and contemporary pragmatism. Acta Philosophica Fennica, 59. Helsinki: The Philosophical Society of Finland.

Popper, K. R. (1975). A Lógica da Descoberta Científica. São Paulo: Cultrix.

Popper, K. R. (1978). Three worlds. In The Tanner Lectures on Human Values (pp. 143-167). Salt Lake City, UT: University of Utah.

Posner, G. J., Strike, K. A., Hewson, P. W., \& Gerzog, W. A. (1982). Accommodation of a scientific conception: Toward a theory of conceptual change. Science Education, 66, 211-227.

Rescher, N. (1995). Pragmatism. In T. Honderich (Ed.), The Oxford companion to philosophy (pp. 710-713). Oxford: Oxford University Press.

Rommetveit, R. (1979). On the architecture of intersubjectivity. In R. Rommetveit \& R.M. Blakar (Eds.), Studies of language, thought, and verbal communication (pp. 93-108). London: Academic Press.

Sepulveda C., Mortimer, E. F., e El-Hani, C. N. (2007). Construção de um perfil para o conceito de adaptação evolutiva. In: E. F. Mortimer (Ed.), Anais do VI Encontro Nacional de Pesquisa em Educação em Ciências. Belo Horizonte, MG: ABRAPEC.

Shrader-Frechette, K., \& McCoy, E. D. (1994). Applied ecology and the logic of case studies. Philosophy of Science, 61, 228-249.

Schutz, A. (1967). The phenomenology of the social world (G. Walsh and F. Lehnert, Trans.). New York, NY: Northwestern University Press.

Tulviste, P. (1991). The cultural-historical development of verbal thinking (M. J. C. Hall, Transl.). New York, NY: Nova Science.

Van Dijk, T. A. (1997). The study of discourse. In T.A. van Dijk (Ed.), Discourse as structure and process (pp. 1-34). London: SAGE Publications.

Vygotsky, L.S. (1978). Mind in society: The development of higher psychological process (M. Cole, V. John-Steiner, S. Scribner \& E. Souberman, Eds.). Cambridge, MA: Harvard University Press.

Vygotsky, L.S. (1987). Thinking and speech (N. Minich, Trans.). In R. W. Rieber \& A. S. Carton (Eds.), The collected 
works of L.S. Vygotsky (pp 39-285).

New York, NY: Plenum Press.

Vigotski, L.S. (2000). A construção do pensamento e da linguagem (P. Bezerra, trad.). São Paulo: Martins Fontes.

Wells, G. (2008). Learning to use scientific concepts. Cultural Studies of Science Education, 3, 329-350.

Wertsch, J. V. (1985). Vygotsky and the social formation of mind. Cambridge, MA: Harvard University Press.

Wertsch, J. V. (1991). Voices of the mind: A sociocultural approach to mediated action. London: Harvester Wheatsheaf.

Whorf, B. L. (1940). Science and Linguistics. Technology Review, 42(6), 229231, 247-248. 